\title{
Risk Management Benefits and Challenges in Malaysia's Landscape Architecture Project
}

\author{
Adam Aruldewan S.Muthuveeran', Osman Mohd Tahir', \\ Roziya Ibrahim¹, Mohd Zairul2
}

1 Department of Landscape Architecture, Faculty of Design and Architecture, Universiti Putra Malaysia, 43400 Selangor, Malaysia

${ }^{2}$ Department of Architecture, Faculty of Design and Architecture,

Universiti Putra Malaysia, 43400 Selangor, Malaysia

aruldewan@yahoo.com; osmanmt@upm.edu.my; roziya@upm.edu.my; m_zairul@upm.edu.my;

Tel: +6017-3125446

\begin{abstract}
The study aims to review risk management benefits and application challenges in Malaysia landscape architecture projects. Twenty-four professional landscape architecture from Klang Valley region interviewed. Then it analysed using content, and thematic analysis method interpreted and concluded. Found a modest project awareness on risk management benefits to improve project outcome, but multiple challenges factor permits effective risk management application. The study recommended an extensive strategy integrating risk management into the landscape project management process formulated in enabling effective application.
\end{abstract}

Keywords: landscape architecture project; risk management; benefit; challenges;

eISSN 2398-4295 @2020. The Authors. Published for AMER ABRA cE-Bs by e-International Publishing House, Ltd., UK. This is an open access article under the CC BY-NC-ND license (http://creativecommons.org/licenses/by-nc-nd/4.0/). Peer-review under responsibility of Association of Malaysian Environment-Behaviour Researchers (AMER); Association of Behavioural Researchers on Asians / Africans / Arabians (ABRA); Centre for Environment-Behaviour Studies (cE-Bs), Faculty of Architecture, Planning \& Surveying, Universiti Teknologi MARA, Malaysia

DOI: https://doi.org/10.21834/ajbes.v5i19.192 


\subsection{Introduction}

Landscape architectural practise is part of the environmental activity to improve the interrelationship between social and cultural influences and landscape setting physical aspects. Recognising environmental concerns such as biodiversity, emissions, energy efficiency, infrastructure, environmental risk, heritage, and innovations in tourism; demand for more socially significant landscape architecture projects have increased over the decades. Landscape architecture projects are seen as dynamic, with unpredictable results and different obstacles due to the variability and difficulty like the projects, resulting in several risks that are bound to occur. As a result of this situation, the element placing risk in a landscape architecture project incorporated with the project procedures, climate and stakeholders. Therefore danger must be handled earlier until it becomes an issue impacting the outcome of the project. Malaysia's landscape architecture project is part of the construction industry, which has recognised a multitude of risks, mostly economic, financial, technological, quality and environmental (Adnan \& Rosman, 2018; Ansah, Sorooshian, Mustafa, \& Duvvuru, 2016; Fadzil, Noor, \& Rahman, 2017; Hasan, Othman, \& Ismail, 2018; Ismail, Ahmad, Janipha, \& Ismail, 2017; Kurzi \& Schroth, 2018; Marmaya \& Mahbub, 2018; Maruthaveeran, 2016; Mohit, 2018; Omer, Adeleke, \& Chia, 2019; Razi, Ali, \& Ramli, 2020; Saaidin, Endut, Samah, Ridzuan, \& Razak, 2016; Sani, Sharip, Othman, \& Hussain, 2018; Shafie, Omar, \& Karuppanan, 2018; Shamsudin \& Majid, 2019; Thani, Mohamad, \& Abdullah, 2017; Wena, Ismail, Hashim, \& Romeli, 2017).

Risk management is a crucial area of project expertise for addressing these problems and their challenges in advance. The primary aim of risk management is to increase project performance through the structured process of risk assessment, review and response to project goals (ISO 31000:2018, 2018; Keers \& van Fenema, 2018; Olechowski, Oehmen, Seering, \& Ben-Daya, 2016; PMI, 2017; Willumsen, Oehmen, Stingl, \& Geraldi, 2019). Given the existence of different risk management principles and guidelines in practice, Malaysia risk management activity in a construction project is at the lowest level. Risk management remains a rhetoric subject and does not practice systematically to its full advantage. Reviewed enormous challenges were enabling effective application of risk management in the Malaysian construction project, found in (Abdul-Rahman, Wang, \& Mohamad, 2015; Adnan \& Rosman, 2018; Fadzil et al., 2017; Goh \& Abdul-Rahman, 2013; Kang, Fazlie, Goh, Song, \& Zhang, 2015; Mohamed, Abd-Karim, Roslan, Mohd Danuri, \& Zakaria, 2014; Omer et al., 2019; Taofeeq, Adeleke, \& Lee, 2020). Understand the current practice of risk management and the implementation of risk management which is essential for project managers to methods for successful application of risk management. Contrary to this, analysis of the advantages of risk management and the design problems specifically relevant to the project in landscape architecture not discussed extensively in the literature.

In Malaysia's landscape architecture initiative, therefore, this study aims to examine existing risk management advantages and implementation challenges. The goals to be accomplished are 1) defining risk management benefits, 2) analysing challenges in managing project risk, and 3) anticipating risk management application challenges. A review performed on the benefits of project risk management and application challenges in Malaysia construction project. This industry is near comparable resemblance with the context of the project's landscape architecture. 


\subsection{Literature Review}

\subsection{Risk Management Benefits In Project}

Risk management is no longer a choice but is a must for any project. The principal objective of risk management is to increase project efficiency (Goh \& Abdul-Rahman, 2013; Ward \& Chapman, 2003) through the systematic method of identifying, analysing, and responding to risk to achieve project objectives (APM, 2010; BS 6079-1:2010, 2010; PMI, 2017). Risk management is a crucial aspect of overall project management that reflects on the possible risk and creates an action plan to avoid potential issues from being issues and adversely affecting the project. It emphasises constructive steps, including risk-based contingency planning (Abdul-Rahman et al., 2015). Such threats, if unmanaged, have the potential to cause a project to deviate from the plan and fail to achieve the established project goals (PMI, 2017), namely deadlines, cost objectives and quality results. The advantages of applying risk management to projects set out in Table 1.

Table 1. Risk management benefits

\begin{tabular}{|c|c|}
\hline Risk Management Benefits & Author \\
\hline \multicolumn{2}{|l|}{ Improves project performances } \\
\hline $\begin{array}{l}\text { Increases the likelihood of achieving } \\
\text { objectives - time, cost, schedule, and quality }\end{array}$ & $\begin{array}{l}\text { Ansah et al. (2016), APM (2010), Du et al. (2016), D. Hillson } \\
\text { (2009), ISO 31000:2018 (2018), Jusoff, Yusuwan, et al. (2008), } \\
\text { Kang et al. (2015), Marcelino-Sádaba et al. (2014), Mills (2007) } \\
\text { Siang \& Ali (2012), S. Ward \& Chapman (2003) }\end{array}$ \\
\hline Encourages project innovation & HB 436:2004 (2005) \\
\hline Improves performance and effectiveness & $\begin{array}{l}\text { Ansah et al. (2016), HB 436:2004 (2005), Mills (2007), Siang and } \\
\text { Ali (2012), Du et al. (2016), Marcelino-Sádaba et al. (2014) }\end{array}$ \\
\hline Enhances project productivity and efficiency & Mills (2007), Loosemore and Cheung (2015) \\
\hline Creates value to the project & $\begin{array}{l}\text { Kang et al. (2015), Siang and Ali (2012), Du et al. (2016), } \\
\text { Marcelino-Sádaba et al. (2014), Willumsen, Oehmen, Stingl, and } \\
\text { Geraldi (2019) }\end{array}$ \\
\hline Improves profits & Kang et al. (2015), Ansah et al. (2016) \\
\hline Improves project performance & $\begin{array}{l}\text { ISO 31000:2018 (2018), Mohamed et al. (2014), Siang and Ali } \\
\text { (2012), Du et al. (2016), Loosemore and Cheung (2015), Marcelino- } \\
\text { Sádaba et al. (2014) }\end{array}$ \\
\hline $\begin{array}{l}\text { Keeps within the stipulated time for } \\
\text { approvals, design and construction }\end{array}$ & Jusoff, Yusuwan, et al. (2008), Marcelino-Sádaba et al. (2014) \\
\hline $\begin{array}{l}\text { Meets the required technical standards for } \\
\text { quality, function, fitness for purpose }\end{array}$ & Ansah et al. (2016), Jusoff, Yusuwan, et al. (2008) \\
\hline
\end{tabular}

\section{Improves project management}

Encourages proactive management

Improves mandatory and voluntary reporting and documentation

Improves governance
ISO 31000:2018 (2018), Siang and Ali (2012), Du et al. (2016), Loosemore and Cheung (2015)

ISO 31000:2018 (2018), Jusoff, Yusuwan, et al. (2008), Dyer (2017)

ISO 31000:2018 (2018), Siang and Ali (2012), Ansah et al. (2016), Dyer (2017), Du et al. (2016), Loosemore and Cheung (2015) 
Improves project decision making - accurate, HB 436:2004 (2005), ISO 31000:2018 (2018), Mills (2007), reliable, and systematic Mohamed et al. (2014), Siang and Ali (2012), Ward and Chapman (2003), Ansah et al. (2016), Dyer (2017), Du et al. (2016), Loosemore and Cheung (2015), Marcelino-Sádaba et al. (2014)

Improves controls and understanding of the APM (2010), Hillson (2009), ISO 31000:2018 (2018), Mills (2007), project Ward and Chapman (2003), Dyer (2017), Marcelino-Sádaba et al. (2014)

Improves and controls outcomes of project HB 436:2004 (2005), Siang and Ali (2012), Dyer (2017) issues

Enables better informed and more believable APM (2010), HB 436:2004 (2005), Hillson (2009), ISO 31000:2018 planning for schedules and budgets (2018), Siang and Ali (2012), Ansah et al. (2016)

Assists for most suitable types of contract selection

Framework for data acquisition and reference for a future project APM (2010), Hillson (2009), Du et al. (2016)

Clarifies the initial thinking process

APM (2010), Hillson (2009), Siang and Ali (2012), Ward and Chapman (2003)

Ward and Chapman (2003), Dyer (2017)

Clearer project communications

Ward and Chapman (2003), Dyer (2017), Loosemore and Cheung (2015), Marcelino-Sádaba et al. (2014)

Selecting a suitable type of contract

Siang and Ali (2012)

Enables a more objective comparison of alternatives

APM (2010), Hillson (2009)

Formulation of practical cost and schedule strategy

Siang and Ali (2012), Dyer (2017)

Reviews project financial stand

Siang and Ali (2012), Dyer (2017), Marcelino-Sádaba et al. (2014)

\section{Managing risk effectively}

Active response and plan to risk

Mills (2007), Siang and Ali (2012), Dyer (2017)

Enabling efficient risk management and construction process.

Improves risk assessment and evaluation justification

ISO 31000:2018 (2018), Siang and Ali (2012)

APM (2010), Hillson (2009), Mills (2007)

Effectively allocates and uses resources for ISO 31000:2018 (2018)

risk treatment

Identifies and allocates responsibility to the best risk owner

Improves the identification of threats and opportunity

ISO 31000:2018 (2018), ISO 31000:2018 (2018), HB 436:2004

Provides a fresh view of the personnel issues APM (2010), Hillson (2009)

in a project

Handles the risks from uncertainty efficiently APM (2010), Hillson (2009), Mohamed et al. (2014) and successfully

Facilitates greater risk-taking, instead of $\quad$ APM (2010), Hillson (2009) keep avoiding

\section{Project protection}

Enhances health and safety performance 
Improves loss prevention and incident management

Reduces unwanted surprises

Protects from litigation consequences

Secures accountability and assurance

Compliance with corporate governance requirements

Environmental protection

\section{Enhance organisation culture}

Improves organisational learning

Improves personal wellbeing

Improves organisational resilience

Improves corporate experience and general communication

A less stressful working environment

\section{Enhances business}

Minimises financial losses

Improves economy, profitability, and

efficiency

Enhances business reputation and credibility APM (2010), HB 436:2004 (2005), Hillson (2009), Siang and Ali

Enhances potential for future business

\section{Manages stakeholders}

Better customer relations

Improves stakeholder confidence and trust

Improves stakeholder relationships

Better customer relations

Avoids project stakeholder dissatisfaction
(2012), Loosemore and Cheung (2015),

ISO 31000:2018 (2018)

HB 436:2004 (2005), Dyer (2017)

HB 436:2004 (2005)

HB 436:2004 (2005)

Ward and Chapman (2003)

ISO 31000:2018 (2018), Jusoff, Yusuwan, et al. (2008)

APM (2010), Hillson (2009), ISO 31000:2018 (2018)

HB 436:2004 (2005), Ward and Chapman (2003), Dyer (2017)

ISO 31000:2018 (2018), Dyer (2017)

APM (2010), Hillson (2009), Ward and Chapman (2003), Dyer

(2017)

APM (2010), Hillson (2009)

ISO 31000:2018 (2018), Willumsen et al. (2019)

HB 436:2004 (2005), Siang and Ali (2012), Ansah et al. (2016)

APM (2010), Hillson (2009)

APM (2010), Hillson (2009), Du et al. (2016)

ISO 31000:2018 (2018), Willumsen et al. (2019)

HB 436:2004 (2005), Marcelino-Sádaba et al. (2014), Willumsen et

al. (2019)

APM (2010), Hillson (2009)

Siang and Ali (2012), Willumsen et al. (2019)

Risk management impacts project performance success because the threats that occur in construction projects depend on the performance of the project. Risk management is a strategic decision-making mechanism used most efficiently and acceptably to reduce and handle risks (Hamzah Abdul-Rahman \& Chen Wang, 2015). Failure to handle such risk could lead to financial loss, reputational harm and loss of potential business (Hamzah Abdul-Rahman \& Chen Wang, 2015). According to Dyer (2017), not only the project manager derives the benefits from risk management but also the building projects' clients, consumers and future end-users. Omer et al. (2019) further clarified that when deciding to start a building project, the customer will quickly see the importance of risk management. The writers added that no matter how small or easy a project is, thanks to the involvement of two separate parties, it can still go wrong.

By summary, risk management increases project efficiency through early detection, prevention, and control of the life cycle of a project. It increases the deliverables of a project in 
three ways, including the critical goals of time, expense and efficiency. Risk management plays an essential role in a construction project's decision-making process, as it can impact the project's profitability, efficiency, quality and budget. It is an integral element of value creation by effective decision-making and preparation for the construction sector. A systematic approach to risk management also strengthens and encourages to find more significant opportunities for quality improvement through creativity. This approach helps managers to maximise performance by defining and evaluating a wide variety of problems, which offers a structured basis for informed decision making.

\subsection{Risk Management Application Challenges in Malaysia Construction}

For different construction projects worldwide, risk management has been practised since the 80s and has shown to affect project performance. There is no shortage of risk management program and ready project manager to use it. However, in the Malaysian construction industry, it has not been commonly practiced (Omer et al., 2019), and the industry tends to have a weak reputation in managing risk. Few authors (Abdul-Rahman et al., 2015; Adnan \& Rosman, 2018; Fadzil et al., 2017; Goh \& Abdul-Rahman, 2013; Jusoff et al., 2008; Kang et al., 2015; Mohamed et al., 2014; Omer et al., 2019; Taofeeq et al., 2020), attempted to provide insight into the difficulties and shortcomings associated with the implementation of risk management and the explanations for this in Malaysia's construction projects. Table 2 outlines the problems and drawbacks of a framework for risk management in Malaysia.

Table 2. Risk management application challenges

\section{Challenges and Limitations}

\section{Risk management system}

Much of the practice is ill-structured, and no suitable methods implemented.

Poor reporting, review and monitoring

Lack of / No uniform protocols and procedures.

Unaivailable and not regularly exercised. Abdul-Rahman et al. (2015), Kang et al. (2015)

\section{Managing risk practice}

Informally manages risk, incomplete and unstructured.

Uses quick, easy, and inexpensive methods.

Identifies the unmanaged risk and remains redundant.

Risk handled only when it happens and when it is understood.

Depend on expertise and reasoning of the project manager.

\section{Author}

Abdul-Rahman et al. (2015), Adnan \& Rosman (2018), Goh \& AbdulRahman (2013), Kang et al. (2015), Omer et al. (2019)

Jusoff et al. (2008), Mohamed et al. (2014)

Jusoff et al. (2008), Mohamed et al. (2014)

\section{Risk knowledge}


Limited skills to develop risk strategy and (Abdul-Rahman et al., 2015; Adnan \& Rosman, 2018; Taofeeq et al., 2020) mitigation program.

Lack of knowledge in managing risk causes usage restriction.

\section{Exposure and experience}

No leading know-how.

Low-risk practice exposure.

Lack of experience in early risk detection.

Still a new concept.
(Abdul-Rahman et al., 2015; Adnan \& Rosman, 2018; Fadzil et al., 2017; Goh \& Abdul-Rahman, 2013; Mohamed et al., 2014; Taofeeq et al., 2020)

(Jusoff et al., 2008; Mohamed et al., 2014)

(Abdul-Rahman et al., 2015; Goh \& Abdul-Rahman, 2013; Taofeeq et al., 2020)

(Mohamed et al., 2014)

(Jusoff et al., 2008; Kang et al., 2015; Omer et al., 2019; Taofeeq et al., 2020)

\section{Awareness}

Comfortable with traditional culture and wary of change.

Unsupportive top management and restricted in other industry personnel,

Lack of positive attitude-linked to timeconsuming and costly

Low awareness and hardly justified application value.
(Abdul-Rahman et al., 2015; Adnan \& Rosman, 2018; Fadzil et al., 2017; Goh \& Abdul-Rahman, 2013; Kang et al., 2015; Taofeeq et al., 2020) (Jusoff et al., 2008; Kang et al., 2015; Mohamed et al., 2014; Taofeeq et al., 2020)

(Abdul-Rahman et al., 2015; Fadzil et al., 2017; Goh \& Abdul-Rahman, 2013; Kang et al., 2015; Taofeeq et al., 2020)

(Abdul-Rahman et al., 2015; Fadzil et al., 2017; Goh \& Abdul-Rahman, 2013; Kang et al., 2015; Mohamed et al., 2014; Omer et al., 2019; Taofeeq et al., 2020)

Risk management remains a rhetorical topic in the Malaysian construction industry due to lack of knowledge and awareness of its advantages, leading to a reluctance to adopt it (Adnan \& Rosman, 2018; Jusoff et al., 2008; Siang \& Ali, 2012). Risk management in the Malaysian construction industry is adapted differently and based on client practices, resource distribution and project structure (Jusoff et al., 2008; Taofeeq et al., 2020). They generally adopt simple, rapid, reasonable, and inexpensive methods of identifying risk rather than managing it as a whole (Adnan \& Rosman, 2018; Siang \& Ali, 2012).

All the authors agreed that the biggest challenge in the implementation of risk management is that there are no formal guidelines and standards to be applied in the construction sector in Malaysia. Only particular organisations and on specific project scale sizes manage the risk. It is not adequately managed and does not follow the suggested process due to lack of knowledge on the implementation of risk management and lack of awareness of its benefits. Building project practitioners are, therefore, reluctant to implement risk management into their projects. There is no substantial evidence that formal risk management applied in landscape architecture projects, similar to construction projects.

\subsection{Methodology}

Exploratory case analysis was engaged in the research methodology (Yin, 2016). The study takes a four-stage procedure, namely, preliminary study, data gathering, data analysis, and interpretation. First, a preliminary study that examines the background of the study, the need, 
identifies the gap, and aims and goals. Data collected via a semi-structured interview with 24 professional landscape architect based in the Klang Valley region. Registered interview audios and project documents; transcribed in the text; documented and organised in research software ATLAS.ti 8. Then, a content analysis used to describe and interpret deductive codes, categorise and finalise the topics (Mayring, 2014). Besides, a thematic analysis then used in the search for inductive codes to synthesise and draw thematic maps between the themes. The analysis includes exploring the relationship between the subject categories studied and looking for patterns (Maguire \& Delahunt, 2017). Finally, finding mapped and reported interpretations to discuss the benefits of risk management, application challenges and improvement. The conclusion draws from the goals of research to answer. This study could become a prominent discussion point in the future and a priority. This study restricted by 1) project management of landscape architecture; 2) case project focused on urban landscape architecture preference; and 3) spectrum problems linked to the experience of architectural landscape practitioners.

Twenty-four interviewees were responding based on predetermined sampling criteria from the organisation of landscape architecture. The criteria of the interviewees were; the interviewees were from landscape architecture firms and were professional landscape architects. In their current organisation, they held managerial and decision-making positions, indicating that they influenced the policy and practice on the ground. All the interviewees had more than ten years of industry experience. They had involved from various project sizes, locations and scopes in a full cycle of landscape projects in an urban area within Klang Valley, Malaysia. Data for the interviewees shown in Table 3 below.

Table 3. Interviewees information

\begin{tabular}{|c|c|c|c|c|c|c|c|}
\hline \multirow{2}{*}{$\begin{array}{l}\text { Interviewee } \\
\text { No. }\end{array}$} & \multirow{2}{*}{$\begin{array}{l}\text { Interviewee's } \\
\text { Position }\end{array}$} & \multirow{2}{*}{$\begin{array}{l}\text { Interview } \\
\text { Duration } \\
\text { (hh:mm:ss) }\end{array}$} & \multicolumn{2}{|c|}{ Interviewee's Background } & \multicolumn{3}{|c|}{$\begin{array}{c}\text { Interviewee's } \\
\text { Organisation Background }\end{array}$} \\
\hline & & & Education & $\begin{array}{l}{ }^{1} \text { Years of } \\
\text { Experience }\end{array}$ & $\begin{array}{c}{ }^{2} \text { Years } \\
\text { Established }\end{array}$ & $\begin{array}{l}{ }^{3} \text { Headcount } \\
\text { Size }\end{array}$ & $\begin{array}{l}{ }^{4} \text { Total Ongoing } \\
\text { Project }\end{array}$ \\
\hline L01 & Director & $0: 40: 08$ & Abroad & Expert & Established & Small & Medium \\
\hline L02 & $\begin{array}{l}\text { Project } \\
\text { Director }\end{array}$ & $0: 58: 11$ & Local & Intermediate & Established & Small & Medium \\
\hline L03 & Director & 1:13:19 & Abroad & Expert & Established & Medium & High \\
\hline L04 & Director & 1:19:44 & Local & Expert & Established & Small & Medium \\
\hline L05 & Principal & 1:02:32 & Local & Intermediate & New & Small & Low \\
\hline L06 & Director & 1:01:02 & Local & Expert & Established & Small & Low \\
\hline L07 & Director & $0: 40: 28$ & Local & Intermediate & New & Micro & Medium \\
\hline L08 & Director & $1: 16: 52$ & Local & Intermediate & New & Micro & Low \\
\hline L09 & Director & $0: 55: 53$ & Abroad & Expert & New & Small & Low \\
\hline L10 & Director & $0: 44: 45$ & Abroad & Expert & Intermediate & Small & Medium \\
\hline L11 & Associates & $0: 50: 19$ & Local & Intermediate & Established & Small & Medium \\
\hline L12 & $\begin{array}{l}\text { Head of } \\
\text { Contract }\end{array}$ & $0: 41: 42$ & Local & Intermediate & New & Small & Medium \\
\hline L13 & Director & 1:11:16 & Abroad & Expert & Intermediate & Small & Low \\
\hline L14 & Director & $0: 55: 13$ & Local & Intermediate & New & Small & Medium \\
\hline L15 & Director & $0: 44: 42$ & Local & Expert & Established & Small & High \\
\hline L16 & Director & 1:13:45 & Local & Intermediate & Intermediate & Micro & Medium \\
\hline L17 & Principal & $1: 29: 10$ & Local & Intermediate & Intermediate & Small & Medium \\
\hline
\end{tabular}


S. Muthuveeran, A.A., et.al., Asian Journal of Behavioural Studies (AjBeS), 5(19) May/Aug 2020 (pp.25-43)

\begin{tabular}{|c|c|c|c|c|c|c|c|}
\hline L18 & Director & 1:06:52 & Local & Intermediate & New & Micro & Low \\
\hline L19 & $\begin{array}{l}\text { Principal } \\
\text { Director }\end{array}$ & $1: 47: 07$ & Abroad & Expert & Established & Small & Medium \\
\hline L20 & Director & $1: 47: 11$ & Local & Intermediate & New & Small & Medium \\
\hline L21 & Director & 1:18:51 & Abroad & Expert & Established & Small & High \\
\hline L22 & $\begin{array}{l}\text { Managing } \\
\text { Director }\end{array}$ & $1: 38: 42$ & Local & Expert & Established & Medium & High \\
\hline L23 & 'Director & 1:05:04 & Local & Intermediate & New & Micro & Low \\
\hline L24 & Director & 1:05:47 & Local & Intermediate & Intermediate & Small & Medium \\
\hline \multirow[t]{4}{*}{ Notes: } & \multicolumn{7}{|c|}{${ }^{1}$ Beginner (< 10 years) / Intermediate $(10<20$ years) / Expert (> 20 years $)$} \\
\hline & \multicolumn{7}{|c|}{${ }^{2}$ New $(<10$ years) / Intermediate $(10<20$ years) / Established ( $>20$ years $)$} \\
\hline & \multicolumn{7}{|c|}{${ }^{3}$ Micro $(<5)$ / Small $(5<30)$ / Medium $(30<75)$ : according to Malaysia's SME classification (SME, 2013) } \\
\hline & \multicolumn{7}{|c|}{${ }^{4}$ Low $(<20) /$ Medium $(20<40) /$ High $(>40)$} \\
\hline
\end{tabular}

\subsection{Results}

Interviewees asked about their views about the benefits of risk management and the application challenges. Their responses addressed in three areas, namely the benefits of risk management, the challenges of managing risk and the expected challenges of implementing risk management.

\subsection{Benefits of Risk Management towards Project}

The research explored the possible benefits of risk reduction in the reduction of landscape projects. The interviewees asked to share their views on the benefits they would reap from integrating risk reduction in projects. The study coded a total of 135 benefits, as shown in Table 4, which classified into eight categories.

Table 4. Benefits of risk management

\begin{tabular}{|c|c|}
\hline Interviewees & Interviewees' Feedback \\
\hline & Improves project control and management \\
\hline L01, L04, L08, L12, L15, L16, L19 & Better control and governance \\
\hline L05, L12, L14, L17, L21 & Improves project management \\
\hline L01, L03, L08, L16, L21 & Minimises project disruption \\
\hline L01, L03 & Practical treatment strategy in design and planning \\
\hline L04, L08 & Improves project understanding \\
\hline L04, L07, L16 & Project's operational effectiveness and efficiency \\
\hline L07 & Better control over technical error \\
\hline L13 & Manages to project cash flow \\
\hline L04, L08 & Avoids and reduces project impact \\
\hline \multirow[t]{2}{*}{ L01 } & Manages a big project effectively. \\
\hline & Improve the project's identification of opportunities and threats \\
\hline $\begin{array}{l}\text { L01, L07, L12, L15, L16, L18, L21, } \\
\text { L22, L23, L24 }\end{array}$ & Manages opportunities and threats effectively. \\
\hline L01, L08 & Assists to detect potential harm and hazard. \\
\hline L01, L21 & Enhances health and safety \\
\hline L21 & Environmental protection \\
\hline
\end{tabular}




\begin{tabular}{l} 
L07, L08, L12, L23 \\
L04, L10, L15, L21 \\
L07, L12, L18, L19, L21, L24 \\
L13 \\
L15, L24 \\
\hline \\
L04, L06, L09, L10, L15, L16, L17, \\
L19, L21, L23, L24 \\
L04, L22, L24 \\
L04, L08, L22, L24 \\
L09, L10, L14, L15, L21, L23, L24 \\
L09, L24 \\
L10, L21 \\
L24 \\
L07 \\
L07, L12, L17
\end{tabular}

L03, L24
L12
L01, L16

Reduces and eliminates the occurrence of risk

Minimises the risk impact

Effective risk treatment strategies

Detects errors or mismanaged site operation

Improves resilience over the risk threat

\section{Improves decision making}

Makes accurate and right project decision

Structure and objectify decision making

Makes strategic planning, design, and coordination input

Profiling and choosing potential projects

Better perception of project risks and consequences

Speeds up decision making

Gives more options on decision making

Quantified and feasible decision making

Better modelling for future projects

\section{Manages project uncertainties}

Detects and controls uncertainties

Reduces uncertainties and changes to feasible risk

Decreases the instability of the project activities

\section{Communication and information management}

L09, L11

Enhances project communication and information sharing

L11

Future project reference

L24

Encourages structured and systematic communication

L12, L15

Avoids miscommunication

\section{Increases the likelihood of achieving objectives}

L03, L05, L06, L08, L15, L17, L24

The project objective is achievable

L02

Better cost estimation

L02

Avoids cost overrun

L04, L13

Improves project performances

L08, L17

On-time project completion

\section{Proactive management}

L01, L09, L10, L21, L24

Encourages proactive project operation

L01, L09

Early resource allocation to treat risk

L01

Better preparedness over the potential risk impact

L10

Project to be more cautious and prepared for unwanted events

L21

Avoids project surprises by early risk identification and treatment

\section{Protects the credibility and reputation of the organisation}

L04

Enhances the organisation's reputation 
L12, L15

L24

L04, L17
Sustains business - enhances cash flow and eliminates loses

Enhances the organisation's portfolio

Improves stakeholders' confidence and trust

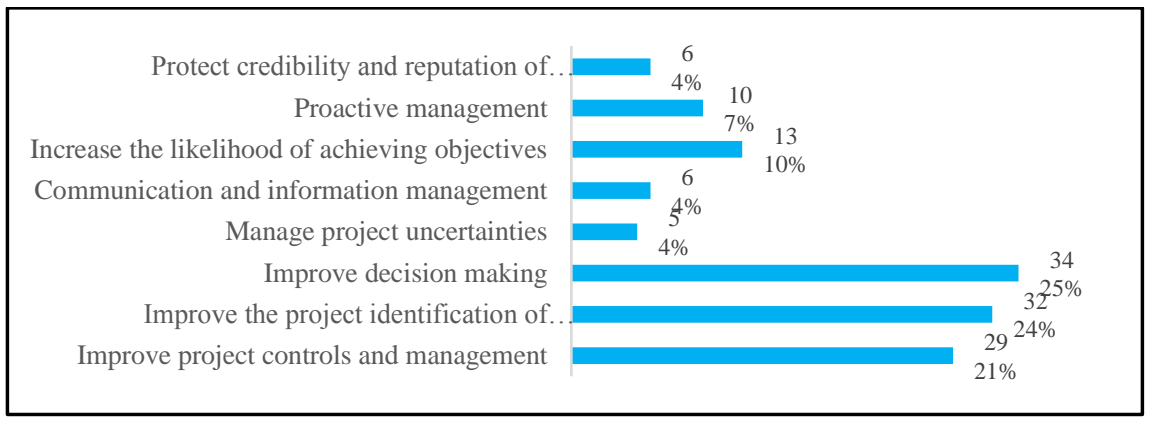

Fig 1. Summary of the significance of risk management

Figure 1 findings indicate that most interviewees see risk management as improving decision making (25\%). This helps with project identification in making correct and appropriate project decisions. Second, risk management is considered as improving the project's identification of risk $(24 \%)$, as active management can maximise opportunities and reduce risks. This would reduce the uncertainties of the project and make them project risks. Efficient risk control can increase the chances of attaining project goals. Third, risk management considered to improve project control (21\%) by improving governance and management while minimising undesirable disruption

\subsection{Challenges When Managing Project Risk}

The research described many challenges the interviewees face when managing the risks of the project. The challenges are divided into six categories, as outlined in Table 5.

Table 5. Challenges when project managing risk

\begin{tabular}{|c|c|}
\hline Interviewees & Interviewees' Feedback \\
\hline & Lack of stakeholder support \\
\hline $\begin{array}{l}\text { L02, L03, L04, L05, L12, } \\
\text { L13, L17, L20, L22 }\end{array}$ & Client not responsive to the identified risk. \\
\hline L02, L13 & Lack of mandate and commitment by the client over the risk. \\
\hline L02, L20 & No contingencies or additional resources allowed to treat the identified risk. \\
\hline L03, L12, L17, L20 & Stakeholder pushing away risk ownership - one party dealt with it. \\
\hline \multirow[t]{2}{*}{ L04, L05, L12, L20, L22 } & Difficulty in convincing the client to agree with risk treatment. \\
\hline & Lack of managing risk experience \\
\hline $\begin{array}{l}\text { L01. L03, L05, L08, L19, } \\
\text { L23 }\end{array}$ & Inexperienced project manager handing project risk and left it unattended \\
\hline L01, L23 & Incompetency to identified risk at early project lifecycle. \\
\hline L12, L20, L23 & Poor risk treatment strategy. \\
\hline L03, L07, L19, L20 & It is challenging to manage - Landscape scope uncertainties and subjective. \\
\hline
\end{tabular}


L01, L03, L06, L08, L10, No specific formal standard procedures and guidelines practised.

L11, L16, L21

L03, L10, L11, L16 Heavy reliance on the project manager's experience and thinking process.

L11, L16

Absent of structured risk process.

L21

None enforcement of risk management policy.

L01 Risk management guideline deemed generic - not suitable for the landscape architecture context.

\begin{tabular}{|c|c|}
\hline & Communication \& information barrier \\
\hline $\begin{array}{l}\text { L01, L02, L07, L15, L20, } \\
\text { L24 }\end{array}$ & Miscommunication causing inefficient risk process. \\
\hline L02, L15, L24 & $\begin{array}{l}\text { Identified risk not recorded and not retrievable for treatment at later phases of the } \\
\text { project. }\end{array}$ \\
\hline L15, L20, L24 & $\begin{array}{l}\text { Project manager not informed of potential risk by others - unknown site condition, } \\
\text { utilities underneath the ground, and changes of the significant scope. }\end{array}$ \\
\hline \multirow[t]{2}{*}{ L01, L07 } & Poor integration between project parties - miscommunication and information sharing. \\
\hline & Risk managed reactively \\
\hline L01, L03, L08, L22, L23 & No attempt to foresee the risk earlier and only managing it when it materialised. \\
\hline L08, L23 & Unavailability of cost and time allocation to treat the surprise risk. \\
\hline \multirow[t]{2}{*}{ L01, L22 } & Poor anticipation and forecasting risk beforehand - inexperienced. \\
\hline & Limited scope of managing risk \\
\hline L08, L20 & The limited risk treatment strategy option towards risks caused by others. \\
\hline L10, L14, L20 & $\begin{array}{l}\text { Small content of landscape architecture scope compared to architecture or engineering } \\
\text { - forced to accept risk rather than avoiding, mitigating, or transferring it. }\end{array}$ \\
\hline
\end{tabular}

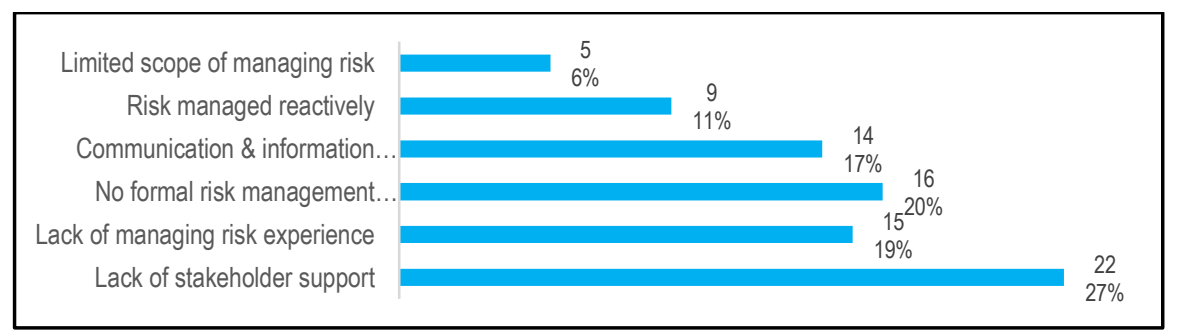

Fig 2. Summary of managing risk challenges

As shown in Figure 2, lack of stakeholder support (27\%), lack of experience (19\%), and no formal guideline $(20 \%)$ described the interviewees as the most common challenges when managing risk in a landscape architectural project. The lack of support from stakeholders for the defined risk further affects risk miscommunication, knowledge sharing barrier and restricted allocation of contingencies for risk management. Such issues are close to the problems facing the building industry in Malaysia, as the literature has illustrated. No standard formal risk management found to restrict challenges toward successful risk management. 


\subsection{Anticipated Risk Management Application Challenges}

The study identified several anticipated risk management application challenges in landscape architecture projects, as expressed by the interviewees. The study coded 143 anticipated challenges and then grouped them into six categories, as shown in Table 6.

Table 6. Anticipated risk management application challenges

\begin{tabular}{ll}
\hline \multicolumn{1}{c}{ Interviewees } & \multicolumn{1}{c}{ Interviewees' Feedback } \\
\hline L03, L06, L22 & $\begin{array}{l}\text { Lack of support and acceptance } \\
\text { Possible rejection - associate risk management as another system for scrutinising } \\
\text { project performance. }\end{array}$ \\
L09, L10, L15, L16, L17, L18, & $\begin{array}{l}\text { Another redundant management system - impractical to project delivery. } \\
\text { L24 }\end{array}$ \\
L17, L20, L22, L24 & The application may disrupt ongoing project progress. \\
L05, L09, L11, L13, L15, L16, & Local construction culture - work with the minimal system and standard. \\
L19, L20, L22 & $\begin{array}{l}\text { Unsupportive client towards application output. } \\
\text { L05, L09, L13, L20 }\end{array}$ \\
L15 & $\begin{array}{l}\text { Client preference towards actual output and financial tolerance management } \\
\text { system like value engineering management and cost management. }\end{array}$ \\
L05, L13, L19, L22 & Comfortable with the current operating system. \\
L06, L09, L15, L16, L17, L21, & Poor motivation and unwilling to learn. \\
\hline L24 &
\end{tabular}

(L01, L09, L23

L03, L05, L09, L15, L17, L20,

L22, L24

L15, L20, L22

L09, L07, L15, L20

L01, L09, L10, L16, L20, L24

L01, L10, L16, L18, L20, L22

\section{Lack of awareness}

Fail to understand the application benefits to project and organisation.

Sceptical on the application - may delay decision making and limit creativity.

May limit project decision making and flexibility due to its rigid structured process.

May limit business opportunities - too concerned about risk rather than the opportunities ahead.

Rejection - application rarely or none used in the landscape industry. Irrelevant application - landscape scope is small, the risk is insignificant, and risk impact is minor.

\section{Resistance to change}

L02, L03, L06, L17, L18, L20, Satisfied with the current project management operation.

L21, L24

L09, L16, L20

Current project operation is sufficient to manage risk.

L16, L21, L23

L10, L16, L18, L20, L24

L16

L13, L18

Rely on the project manager's experience and knowledge.

Unwilling to allocate time and cost.

Challenges to attain the internal operation team's mandate and commitment.

Then the stringent procedure of government client - application disregarded.

\section{Lack of resources}

L02, L05, L06, L09, L11, L15, L17, L18, L20

Regarded risk management application as consuming time and efforts - limited budget.

L06, L09, L10, L11, L17, L18

L04, L05, L06, L09, L10, L11,

L15, L17, L20, L24

L06, L16, L17
Project nature that is rushing and time constraint - no time allowance.

Worried the application requires extensive paperwork and protocol, further delaying the project.

Increases business cost - to employ a specialist to manage risk. 
Limited staff and time constraint in handling multiple projects - application may be put aside.

\section{Lack of knowledge}

L01, L05, L10, L15, L17, L19, Lack of risk and risk management knowledge.

L20, L21

L04, L09, L21

L06, L15, L17, L21

L16, L19

Lack of risk management exposure - application is new to the industry.

Need a great time to understand the risk process.

Difficult to transfer the risk management knowledge to the organisation's project team - to junior and non-technical staff.

L05, L06, L08, L16

\section{Lack of expertise}

No specialised landscape expertise to handle risk management - relying on other industries to study their risk. management.

Figure 3 findings show that the problems in the implementation of risk management differ due to internal as well as external factors. The interviewers were most concerned about the lack of support and acceptance for the application for risk management (27\%). Poor awareness (21\%) of the principles and advantages of risk management further delays the successful implementation of risk management. Lack of resources $(21 \%)$, such as limited budget and allocation of time, is also a threat to risk management practice. The remaining challenges in adopting a risk management application are resistance to change, lack of expertise and lack of knowledge. The anticipated application challenges are close to the problems facing the construction industry in Malaysia, as discussed in the literature. The anticipated challenges of risk management application are often close to the project mentioned above issues that relate to low client participation and understanding of the landscape scope.

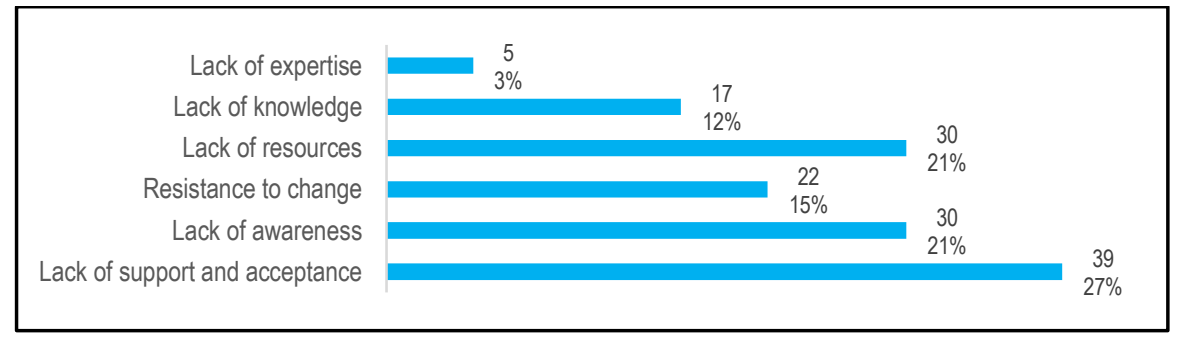

Fig. 3. Summary of anticipated risk management application challenges

\subsection{Discussion}

The study found that the interviewees highly recognised risk management application benefits for their projects to improve decision making, improve risk identification, reduce the uncertainties and took better control of project outcome. This similar benefits found in literature whereby risk management improves project performance, improve project deliverables, assist decision-making and enhance productivity, performance, quality, and the budget of the project (Ansah et al., 2016; 
APM, 2010; Du et al., 2016; Dyer, 2017; Hillson, 2009; Kang et al., 2015; Marcelino-Sádaba et al., 2014; Siang \& Ali, 2012; Ward \& Chapman, 2003; Willumsen et al., 2019). Full awareness of the risk management application benefits will lead to affirmative acceptance and practice by the project manager, rather than treating the application as another redundant management system. Hence, knowledge and practice of risk management can enhance their understanding of the significance of the application.

Meanwhile, reviewed lack of stakeholder's support, lack of risk experience, communication barrier and scope definition found to be primary challenges when managing risk. The challenges observed related to human factor reason from project culture, personal perception and poor clientconsultant engagement. The mismanaged project risk further implicate effective risk management application. Lack of support, acceptance, resistance to change, poor risk management awareness, lack of knowledge, resources and expertise constrained effective risk management application. Added up to all identified challenges, the most significant risk management application challenges are there is no formal risk management system applied into landscape architecture project. This similar challenges found in Malaysia construction project where riskmanaged reactively, ill-structured process and informal practice manner due to unavailable formal risk management application (Abdul-Rahman et al., 2015; Adnan \& Rosman, 2018; Fadzil et al., 2017; Goh \& Abdul-Rahman, 2013; Kang et al., 2015; Mohamed et al., 2014; Omer et al., 2019; Taofeeq et al., 2020). As a result, the mismanaged project risk and ineffective risk management application challenge subsequently impact the project performances. Beyond the project completion, the hidden project risk that project failed to unanticipated will potentially lead to significant consequences such as litigation implication, environmental degradation, injury, loss of property and socio-culture. Therefore, there is a need to raise the awareness of landscape architect professionals in Malaysia about the benefits of risk management application and employing the appropriate method to manage project risk. The improvement of managing risk practice by enhancing risk mandate and commitment, awareness, integration to the current process, communication and information management.

Thus, recognising the benefits of risk management and facing its application challenges, the formulation of the best strategy was chosen to incorporate risk management into projects of landscape architecture. A risk management system that was integrating risk management processes into project management processes to be built to match the context of landscape architecture. The new structure for risk management will be versatile, standardised and consistent with the context of the organisation. Improvement in risk management practices can be accomplished by strengthening the risk mandate and dedication, building knowledge, incorporating into existing processes, and promoting communication and information management, in addition to system growth. Such measures should ensure the efficacy of the application built for risk management. Creation of the risk management framework development and risk management practice improvement were considered in designing a practical application for risk management, as illustrated in Figure 4. 


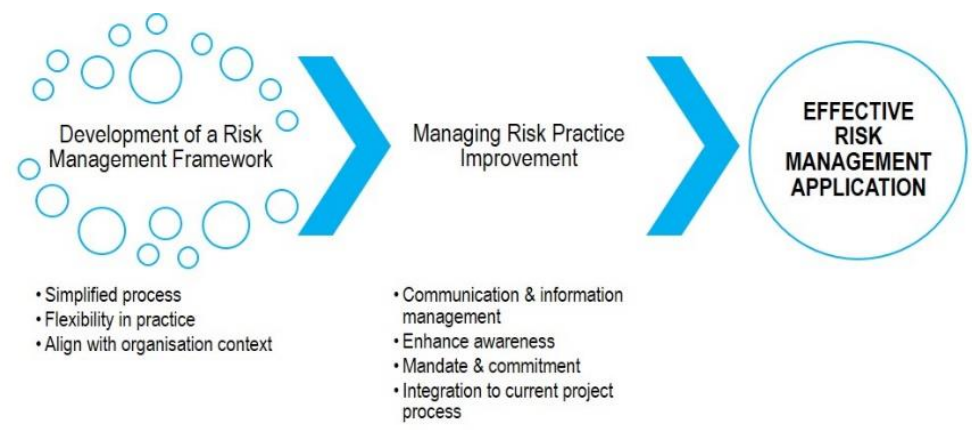

Fig. 4. An effective risk management application

\subsection{Conclusion}

This research surmised modest knowledge of risk management benefits to landscape architecture project managers to enhance project outcome. However, due to no formal risk management applied, multiple challenges factor allows for effective application of risk management in a landscape architecture project. Despite the introduction of formal processes of risk management, however, most risk management is practised in an ill-structured method and is usually carried out informally. This research offers relevant and useful insight into a practical knowledge of the real benefits of risk management, application challenges and suggest improvement in the Malaysian landscape architecture project. An extensive strategy to risk management application into landscape architecture project has been devised by recognising specific advantages and defining design problems for the industry. For effective risk management application, recommended the project organisation to have a formal risk management system to landscape architectural context.

Further study devoted to formulating the best strategy for integrating risk management into project management of landscape architecture. This strategy is essential for project manager landscape architecture to manage their risk effectively in order to improve the performance of the project.

\section{Acknowledgement}

We appreciate the financial support from Geran Putra-Inisiatif Putra Siswazah (GP-IPS), Universiti Putra Malaysia (Project Number: GP-IPS/2018/9617500) for this study

\section{References}

Abdul-Rahman, H., Wang, C., \& Mohamad, F. S. (2015). Implementation of Risk Management in Malaysian Construction Industry: Case Studies. Journal of Construction Engineering, 2015(1), 7. https://doi.org/10.1155/2015/192742

Adnan, H., \& Rosman, M. R. (2018). Risk management in Turnkey projects in Malaysia. WSEAS Transactions on Business and Economics, 15, 35-43. 
Ansah, R. H., Sorooshian, S., Mustafa, S. Bin, \& Duvvuru, G. (2016). Assessment of Environmental Risks in Construction Projects: A Case of Malaysia. In Proceedings of the International Conference on Industrial Engineering and Operations Management (pp. 752-763).

APM. (2010). Project Risk Analysis and Management Guide. (APM Risk Management Specific Interest Group, Ed.), (reprinted 2007, 2009, 2010) (2nd ed.). Buckinghamshire: Association for Project Management.

BS 6079-1:2010. (2010). Project Management - Part 1: Principles And Guidelines For The Management Of Projects (3rd ed.). London W4 4AL, UK: British Standards Institution (BSI). Retrieved from www.bsi- group.com/standards

Du, L., Tang, W., Liu, C., Wang, S., Wang, T., Shen, W., ... Zhou, Y. (2016). Enhancing engineer-procure-construct project performance by partnering in international markets: Perspective from Chinese construction companies. International Journal of Project Management, 34(1), 30-43. https://doi.org/10.1016/j.jproman.2015.09.003

Dyer, R. (2017). Cultural sense-making integration into risk mitigation strategies towards megaproject success. International Journal of Project Management, 35(7), 1338-1349. https://doi.org/10.1016/j.jproman.2016.11.005

Fadzil, N. S., Noor, N. M., \& Rahman, I. A. (2017). Need of risk management practice amongst bumiputera contractors in Malaysia construction industries. In IOP Conference Series: Materials Science and Engineering (Vol. 271, p. 7). https://doi.org/10.1088/1757-899X/271/1/012035

Goh, C. S., \& Abdul-Rahman, H. (2013). The Identification and Management of Major Risks in Malaysian Construction Indusrty. Journal of Construction in Developing Countries, 18(1), 19-32.

Hasan, R., Othman, N., \& Ismail, F. (2018). Choosing Tree for Urban Fabric: Role of Landscape Architect. In 6th AicQoL2018Perhentianlsland, 03-04 March 2018 / E-BPJ, 3(7) (pp. 199-207).

HB 436:2004. (2005). Risk Management Guidelines Companion to AS/NZS 4360:2004. (S. A. N. Zealand, Ed.). Sydney, NSW: Standards Australia International Ltd. https://doi.org/10.1016/B978-075067555-0/50157-2

Hillson, D. (2009). Managing risk in projects. Project Management Journal, 46(March), 84-96. https://doi.org/10.1002/pmj

Ismail, F., Ahmad, N., Janipha, N. A. I., \& Ismail, R. (2017). The Behavioural Factors ' Characteristics of Safety Culture. Journal of ASIAN Behavioural Studies (JABs), 2(4), 91-98.

ISO 31000:2018. (2018). ISO 31000:2018 Risk management - Guidelines. (ISO/TC 262 Risk Management, Ed.) (2nd ed.). Geneva 20: International Organization for Standardization (ISO). Retrieved from www.iso.org

Jusoff, K., Yusuwan, N. M., Adnan, H., \& Omar, A. F. (2008). Clients' Perspectives of Risk Management Practice in Malaysian Construction Industry. Journal Politic and Law, 1(3), 121-130. https://doi.org/10.5539/jpl.v1n3p121

Kang, B. G., Fazlie, M. A., Goh, B. H., Song, M. K., \& Zhang, C. (2015). Current Practice of Risk Management in the Malaysia Construction Industry - The Process and Tools/Techniques. International Journal of Structural and Civil Engineering Research, 4(4), 371-377. https://doi.org/10.18178/ijscer.4.4.371-377

Keers, B. B. M., \& van Fenema, P. C. (2018). Managing risks in public-private partnership formation projects. International Journal of Project Management, 36(6), 861-875. https://doi.org/10.1016/j.jproman.2018.05.001

Kurzi, N. S., \& Schroth, O. (2018). Maintenance and Personal Safety in Neighborhood Parks: A literature and case study of MPSJ. Asian Journal of Quality of Life (AjQoL), 3(13), 107-116. https://doi.org/10.21834/ajqol.v3i13.167

Loosemore, M., \& Cheung, E. (2015). Implementing systems thinking to manage risk in public private partnership projects. 
International Journal of Project Management, 33(6), 1325-1334. https://doi.org/10.1016/j.jproman.2015.02.005

Maguire, M., \& Delahunt, B. (2017). Doing a Thematic Analysis: A Practical, Step-by-Step. The All Ireland Journal of Teaching and Learning in Higher Education, 8(3), 3351-33514. Retrieved from http://ojs.aishe.org/index.php/aishej/article/view/335

Marcelino-Sádaba, S., Pérez-Ezcurdia, A., Echeverría Lazcano, A. M., \& Villanueva, P. (2014). Project risk management methodology for small firms. International Journal of Project Management, 32(2), 327-340. https://doi.org/10.1016/j.jproman.2013.05.009

Marmaya, E. A., \& Mahbub, R. (2018). Evaluation of Environmental Impact and Risk Assessment Methods of Industrial Buildings in Malaysia. Asian Journal of Quality of Life (AjQoL), 3(13), 39-47. https://doi.org/10.21834/ajqol.v3i13.160

Maruthaveeran, S. (2016). The Perception of Social Safety in a Green Environment: A preliminary study at the Kepong Metropolitan Park. Asian Journal of Environment-Behaviour Studies (AjE-Bs), 1(1), 99-111. https://doi.org/10.21834/ajebs.v111.171

Mayring, P. (2014). Qualitative Content Analysis: Theoretical Foundation, Basic Procedures and Software Solution. Klagenfurt: Social Science Open Access Repository (SSOAR).

https://doi.org/http://dx.doi.org/10.4135/9781446282243.n12

Mills, A. (2007). A systematic approach to risk management for construction. Structural Survey, 19(5), 245-252. https://doi.org/10.1108/02630800110412615

Mohamed, O., Abd-Karim, S. B., Roslan, N. H., Mohd Danuri, M. S., \& Zakaria, N. (2014). Risk management: Looming the modus operandi among construction contractors in Malaysia. International Journal of Construction Management, 15(1), 82-93. https://doi.org/10.1080/15623599.2014.967928

Mohit, M. A. (2018). Quality-of-Life Studies in Natural and Built Environment: Challenges and emerging issues. Asian Journal of Behavioural Studies (AjBeS), 3(10), 147-157.

Olechowski, A., Oehmen, J., Seering, W., \& Ben-Daya, M. (2016). The professionalization of risk management: What role can the ISO 31000 risk management principles play? International Journal of Project Management, 34(8), 1568-1578. https://doi.org/10.1016/j.jproman.2016.08.002

Omer, M. S., Adeleke, A. Q., \& Chia, K. L. (2019). Level of Risk Management Practive in Malaysia Construction INdustry From A Knowledge-Based Perspective. Journal of Architecture, Planning and Construction Management, 9(1), 112-129.

PMI. (2017). A Guide To The Project Management Body Of Knowledge (PMBOK Guide). (PMBOK, Ed.) (6th ed.). Pennsylvania 19073-3299 USA: Project Management Institute, Inc. https://doi.org/10.1002/pmj.21345

Razi, P. Z., Ali, M. I., \& Ramli, N. I. (2020). Incorporation of Risk Index for Risk Response and Risk Mitigation Strategies of Public-Private Partnership (PPP) Housing Construction Project in Malaysia. In IOP Conference Series: Materials Science and Engineering (Vol. 712, p. 012031). https://doi.org/10.1088/1757-899x/712/1/012031Risk management Guidelines. (n.d.).

Saaidin, S., Endut, I. R., Samah, S. A. A., Ridzuan, A. R. M., \& Razak, N. N. A. (2016). Risk Variable On Contractor's Tender Figure In Malaysia. Jurnal Teknologi (Sciences \& Engineering), 2(78:5), 85-89. https://doi.org/eISSN 2180-3722

Sani, J. A., Sharip, N. A. A., Othman, N., \& Hussain, M. R. M. (2018). Relationship between Types of Organization with the Quality of Soft-scape Construction Work in Malaysia. Asian Journal of Quality of Life (AjQoL), 3(12), 137-146. https://doi.org/10.21834/ajqol.v3i12.150 
Shafie, F. A., Omar, D., \& Karuppanan, S. (2018). Environmental Risk Evaluation of a Sanitary Landfill using Life Cycle Analysis Approach. Asian Journal of Environment-Behaviour Studies (AjE-Bs), 3(8), 89-95. https://doi.org/10.21834/ajebs.v3i8.282

Shamsudin, N. M., \& Majid, F. A. (2019). Effectiveness of Construction Safety Hazards Identification in Virtual Reality Learning Environment. In 8th AcEBs2019Langkawilsland, Malaysia 18-19 Dec 2019 / E-BPJ, 4(12) (pp. 375-381).

Siang, L. C., \& Ali, A. S. (2012). Implemention of risk management in the malaysian construction industry. Journal of Surveying, Construction \& Property, 3(1), 1-15. https://doi.org/10.1155/2015/192742

SME. (2013). Guideline for New SME Definition. Putrajaya: National SME Development Council (NSDC). Retrieved from http://www.smecorp.gov.my/vn2/sites/defaulttfiles/Guideline_for_New_SME_Definition_7Jan2014.pdf

Taofeeq, D. M., Adeleke, A. Q., \& Lee, C. K. (2020). The synergy between human factors and risk attitudes of Malaysian contractors': Moderating effect of government policy. Safety Science, 121(September 2019), 331-347. https://doi.org/10.1016/j.ssci.2019.09.016

Thani, S. K. S. O., Mohamad, N. H. N., \& Abdullah, S. M. S. (2017). Influence of Urban Landscapes to Microclimatic Variances in a Tropical City. Asian Journal of Behavioural Studies (AjBeS), 2(7), 31-41.

Ward, S., \& Chapman, C. (2003). Transforming project risk management into project uncertainty management. International Journal of Project Management, 21(2), 97-105. https://doi.org/10.1016/S0263-7863(01)00080-1

Wena, J., Ismail, F., Hashim, N., \& Romeli, N. (2017). Adaptation Criteria towards Quality Culture for the Malaysian Contractors. In 5th AicQoL2017Bangkok, 25-27 February 2017 / E-BPJ, 2(5) (pp. 79-83). e-IPH Ltd. https://doi.org/10.21834/e-bpj.v2i5.676

Willumsen, P., Oehmen, J., Stingl, V., \& Geraldi, J. (2019). Value creation through project risk management. International Journal of Project Management, 37(5), 731-749. https://doi.org/10.1016/j.jproman.2019.01.007

Yin, R. K. (2016). Qualitative Research from Start to Finish (2nd ed.). New York, NY: The Guilford Press. https://doi.org/10.1007/s13398-014-0173-7.2 